\title{
Research on Cooperative Procurement and Warehouse Management of Enterprise Supply Chain
}

\author{
Jikai Huang \\ School of Economics and Management, \\ Beijing Jiaotong University, \\ Haidian District, Beijing, China \\ E-mail: hjk03341@163.com
}

\begin{abstract}
Collaborative management of supply chain refers to the coordination and mutual efforts made by each node in the supply chain in order to improve the overall competitiveness of the supply chain. Each node in the supply chain forms a network cons ortium by means of enterprise agreement or syndication. It is a dynamic network composed of customers, suppliers, cooperative enterprises and the information flow between them. Based on the theory of network economy, the purpose of this paper is to study supply chain collaborative procurement management and collaborative warehouse management. This paper coordinated the warehouse management control model by cons tructing supply chain collaborative procurement. Finally, a coordinated implementation strategy for enterprise supply chain was obtained.
\end{abstract}

Keywords-Supply Chain Management; Collaborative Procurement; Collaborative Warehousing; Network Economy

\section{INTRODUCTION}

In the current market, there are a series of problems such as increasing production volume without increasing profits, excess inventory, high logistics and management costs, and lack of core technologies. The current fiercely competitive market environment forcing Chinese enterprises to actively optimize the supply chain operation mechanism and gradually achieve supply chain collaborative management. The original business to a lot of their own material processing business outsourcing. From a supply chain perspective, this means that the supply chain of the enterprise lengthens and its dependence on the entire supply chain across corporate boundaries increases. Enterprise material procurement management for the reduction of total cost of the enterprise, product quality assurance and delivery of the guarantee is more and more important.

Anderson and Lee analyzed the basic conditions for collaborative supply chain, the many challenges faced and the value of the problem ${ }^{[1]}$. In 2000 , Ito and Salleh pointed out that synergy among members of supply chain is the key to effective supply chain management and proposed e-blackboard negotiation based on collaborative supply chain system ${ }^{[2]}$. In 2002, ARC, a well-known consulting firm in the United States, proposed Collaborative Manufacturing Management strategy based on Collaborative Value Network and established CMM model ${ }^{[3]}$. In 2003, R. McIvor et al. studied e-commerce support for collaborative supply chain management ${ }^{[4]}$. In 2004, Turkay M. et. al. Modeled and quantified the synergies among chemical industry firms ${ }^{[5]}$. Akkermans et al. established a theoretical model of supply chain collaboration, focusing on the importance of non-technical factors in achieving synergy ${ }^{[6]}$ Yi Dongbo conducted a modeling analysis of two-level inventory coordinated control for stochastic demand ${ }^{[7]}$. Tang Xiaobo and Huang Yuanyuan elaborated the bottleneck of collaborative supply chain management, and gave the supply chain collaborative strategy and collaborative performance evaluation model ${ }^{[8]}$. Liu Shenghua analyzed the obstacles of supply chain coordination in e-commerce environment, and focused on the collaborative management of supply chain from two aspects of soft constraints and hard constraints ${ }^{[9]}$. Tang Jiansheng et al. analyzed the internal motivation of supply chain collaboration and analyzed the scale of strategic coordination under three different revenue structures from the view of game ${ }^{[10]}$. Zhang Cuihua pointed out the difference between supply chain collaborative management and traditional supply chain management under the premise of the research progress of supply chain collaborative management in China and abroad and analyzed the development trend of supply chain collaborative management ${ }^{[11]}$. Chen Siyun, Shen Simin, February 2007, in the article "Collaborative Cost Management of Automobile Supply Chain Management Based on Target Cost Method", based on the synergetic idea; this paper explores the field of automobile supply chain cost management, Cost management in various enterprises, supply chain procurement, sales, service-specific cost management methods [12]. Sun Q. (2010) put forward the operation mechanism and strategy of collaborative procurement, collaborative warehousing and coordinated transportation in supply chain collaborative management based on the article "Research on Collaborative Management of Automobile Supply Chain Based on Value Network", and established a collaborative supply chain management model ${ }^{[13]}$.

\section{Supply Chain Collaborative Procurement MANAGEMENT MODEL}

The speed and efficiency of procurement of production materials and spare parts and the implementation of 
procurement contracts will have a direct impact on whether enterprises can meet their production needs quickly and flexibly. The purchase cost will directly affect the final costeffectiveness of the enterprise and the final profitability of the entire supply chain. When a company needs to outsource a lot of materials, it is necessary to explore how to adopt different management strategies for different outsourced materials. Only when the strategies are properly applied can the timely procurement of all materials be guaranteed. The classification of purchasing materials is a new classification method and criterion based on ABC classification method. Material classification is based on the importance of the material itself and determine the complexity of the supply market.

According to this classification method, all kinds of materials are basically divided into four categories: strategic materials, important materials, bottlenecks and general materials. And then for different types of materials to adopt different supplier management and procurement and inventory strategy to save costs. The classification of the purchase of materials and the development of different management strategies, it is the choice of suppliers. Supplier selection is a typical multi-factor optimization problem. TOPSIS (Technique for Order Preference by Similarity to Ideal Solution) is a commonly used method in multi-objective decision analysis of finite solutions. The advantage is the ability to rank and compare decision plans. The basic idea of TOPSIS is to consider the distance between the alternative and the ideal and the least desirable simultaneously. The optimal solution should be as close as possible to the ideal solution and as far as possible from the most undesirable solution.

Suppose there are m suppliers and $\mathrm{n}$ evaluation indexes, and the evaluation value of the number $j$ index of the number $i$ supplier in $X_{i j}$, then the evaluation matrix of the indexes of the suppliers is:

$$
X=\left|\begin{array}{cccc}
x_{11} & x_{12} & \cdots & x_{1 n} \\
x_{21} & x_{22} & \cdots & x_{2 n} \\
\vdots & \vdots & \vdots & \vdots \\
x_{1 m} & x_{2 m} & \cdots & x_{m n}
\end{array}\right|
$$

Due to the different dimensions of each evaluation index, in order to facilitate comparison, they need to be normalized by the following formula.

$$
r_{i j}=x_{i j} / \sum_{i=1}^{m} x_{i j}(\mathrm{i}=1,2, \ldots \mathrm{m} ; \mathrm{j}=1,2, \ldots \mathrm{n})
$$

In the choice of suppliers, all enterprises of the importance of the evaluation index will have different evaluation. The traditional TOPSIS method usually adopts expert survey or AHP in determining the weighting factors of evaluation indexes. These methods have large subjective factors, and different people have different opinions on the importance of each index. This paper makes improvements to the TOPSIS method, using the concept of entropy to determine the weight of evaluation indicators and completely avoid the influence of subjective factors. Entropy is a measure of the uncertainty of information using probability Theory. Its data distribution is proportional to the degree of dispersion and uncertainty. The decision-making information of each index can be expressed by its entropy value $e_{j}$ :

$$
e_{j=-k} \sum_{i=1}^{m} r_{i j} \ln r_{i j}(\mathrm{j}=1,2, \ldots \mathrm{n})
$$

Among $k=1 / \ln m$. Once it determined the number of suppliers participating in the selection. $k$ will be a constant, to ensure $0 \leqslant e_{j} \leqslant 1$. The degree of dispersion $d_{j}$ of the evaluation value data of the number $\mathrm{j}$ indicator is expressed as:

$$
d_{j}=1-e_{j}(\mathrm{j}=1,2, \ldots \mathrm{n})
$$

The distribution of the $r_{i j}(i=1,2, \cdots m)$ values of the $\mathrm{j}$ indicator is more dispersed, and the corresponding $d_{j}$ value is larger. It shows that the $\mathrm{j}$ indicator is more important. On the contrary, if the $r_{i j}$ value distribution of the $\mathrm{j}$ index is relatively concentrated, it indicates that the index is of lower importance. If the $r_{i j}$ values are equal, the index evaluation value is concentrated. Indicate that the indicator will not play any role in selecting suppliers. Therefore, the weighting factor for the $\mathrm{j}$ indicator expressed in terms of entropy measures is:

$$
j=d_{j} / \sum_{j=1}^{n} d_{j}=\left(1-e_{j}\right) / \sum_{j=1}^{n}\left(1-e_{j}\right)
$$

After determining the weighting factors of each index, essay consider calculating the matrix of suppliers' weighted evaluation value as:

$$
V=\left|\begin{array}{cccc}
w_{1} r_{11} & w_{2} r_{12} & \cdots & w_{n} r_{1 n} \\
w_{1} r_{21} & w_{2} r_{22} & \cdots & w_{n} r_{2 n} \\
\vdots & \vdots & \vdots & \vdots \\
w_{1} r_{1 m} & w_{2} r_{2 m} & \cdots & w_{n} r_{m n}
\end{array}\right|=\left|\begin{array}{cccc}
v_{11} & v_{12} & \cdots & v_{1 n} \\
X_{21} & x_{22} & \cdots & v_{2 n} \\
\vdots & \vdots & \vdots & \vdots \\
v_{1 m} & v_{2 m} & \cdots & v_{m n}
\end{array}\right|
$$

The most ideal and the most unsatisfactory indicator weighted evaluation set are:

$$
\begin{aligned}
& A^{+}=\left\{v_{1}^{+}, v_{2}^{+}, \cdots, v_{n}^{+}\right\}=\left\{\left(\max _{i} v_{i j} \mid j \in J_{1}\right),\left(\min _{i} v_{i j} \mid j \in J_{2}\right) \mid i=1,2, \cdots, m\right\} \\
& A^{-}=\left\{v_{1}^{-}, v_{2}^{-}, \cdots, v_{n}^{-}\right\}=\left\{\left(\min _{i} v_{i j} \mid j \in J_{1}\right),\left(\max _{i} v_{i j} \mid j \in J_{2}\right) \mid i=1,2, \cdots, m\right\}
\end{aligned}
$$

$J_{1}$ is a set of indicators of benefit factors; $J_{2}$ is a set of indicators of cost factors.

The supplier's evaluation value and the best set of evaluation values can be calculated using the following ndimensional Euclidean formula:

$$
L_{1}^{+}=\sqrt{\sum_{j=1}^{n}\left(v_{i j}-v_{j}^{+}\right)^{2}}(\mathrm{i}=1,2, \cdots \mathrm{m})
$$


The supplier's evaluation value and the least desirable set of evaluation values can be calculated using the following $\mathrm{N}$ dimensional Euclidean formula:

$$
\boldsymbol{L}_{1}^{-}=\sqrt{\sum_{j=1}^{n}\left(v_{i j}-v_{j}^{-}\right)^{2}}(\mathrm{i}=1,2, \cdots \mathrm{m})
$$

The TOPSIS rating for each supplier is calculated as follows:

$$
Y_{1}=L_{1}^{-} /\left(L_{1}^{+}+L_{1}^{-}\right)
$$

At this point, the supplier can be sorted and selected according to the TOPSIS evaluation value.

\section{Supply Chain Collaborative Warehouse MANAGEMENT MODEL}

Enterprise Collaborative Warehousing Management is to use scientific methods to rationally plan, organize, allocate and control the supply, use and management of materials and tools needed in the production process. With a lower cost, timely, appropriate and appropriate supply of supplies needed to ensure the smooth progress of production. The implementation of supply chain coordination and optimization strategy can strengthen the entire industry supply chain management of the production process and reduce the industry's inventory. In the industry supply chain, core enterprises and all nodes establish a complete, timely and accurate information platform to enhance the sharing and transparency of information between upstream and downstream nodes. Upstream and downstream businesses can develop supply and demand plans based on the same source.

In the enterprise inventory system, a complete inventory process, including ordering, purchase, storage, shipping four stages. In the supply stage, it is difficult to determine and control the reasonable inventory, is relatively passive, but in the ordering phase control is feasible and active. Therefore, to determine a reasonable order volume is the key to inventory control. Under different conditions, the establishment of the corresponding inventory model, select the best batch of economic orders, it is the basis for inventory decisions. Based on this idea, this paper considering the enterprise collaborative warehouse management model.

\section{A. Model's Basic Assumptions}

(a.) The model only considers the relationship between the enterprises and their suppliers in the ordering, transportation, storage and shipping, ie, the optimization among upstream enterprises in the supply chain.

(b.) In order to simplify the calculation, the model only considered a two-stage inventory model.

(c.) This model considers only a single material situation. It does not consider the material price discount.

(d.) The model does not specifically consider the impact of uncertain events.

(e.) The starting point for the study of warehouse management in this model is: after drawing up the production plan of a certain project, formulating the material ordering plan according to the production technology to optimize the warehouse management. It does not take into account the material savings that may result from changing the design, adopting new processes or new technologies.

(f.) Suppose the material is consumed at a constant rate.

\section{B. Modeling and Solution}

Enterprises in the supply chain for storage coordination, it is necessary to consider all the supply chain inventory in transit, work in progress inventory, on-site inventory. When enterprises are purchasing raw materials, the order quantity should meet a minimum and maximum restraint quantity in order to make the raw material production line of the supplier saturated evenly. In order for the supplier to arrange the economy of production and product transportation, the order quantity of the enterprise should meet a certain modulus.

From the perspective of supply chain, the establishment of enterprise collaborative warehouse management model can be seen as the deadline (resource-constrained network planning optimization model), and genetic algorithms for raw materials ordering program selection decision. Enterprise collaborative warehouse management process optimization process is as follows:

1) Confirmation of the objective function:

The inventory cost is mainly composed of the order cost $T C_{0}$, the purchase cost $T C_{1}$, the storage cost $T C_{2}$ and the out-of-stock cost $T C_{3}$. Therefore, the objective function of this model is:

$$
\text { MinimizeC }=T C_{0}+T C_{1}+T C_{2}+T C_{3}
$$

The amount of material used for a given project is fixed. Then the purchase price of the material will not change with the number of purchases (regardless of price changes). Therefore, the purchase cost of the material in the established inventory cost model will not be considered.

\section{2) Confirmation constraints:}

Considering inventory, transportation and production capacity constraint, establish inventory cost control model. For core enterprises, the established cost control model should meet the following conditions:

(a) The relaxation time for a job is: the actual start of the job should be later than the earliest start of the job, and within the relaxation time.

$$
T_{E i-j} \leq T_{S i-j} \leq T_{E i-j}+R_{S i-j}
$$

In the formula, $T_{E i-j}$ is the earliest possible start time of $i-j$ work; $T_{S i-j}$ is the actual start time of $i-j$ work; and $R_{S i-j}$ is the relaxation time range of $i-j$ work.

(b) After all the predecessor activity for a job has completed, it must begin before the latest required time. That is: 
$\max \left\{T_{\text {sh-i }}+t_{\text {eh-i }}\right\} \leq T_{S i-j} \leq T_{L i-j}$

In the formula, $t_{e h-i}$ is the duration of the work; $T_{L i-j}$ is the latest start-up time of $i-j$ work; and $h-i$ is the predecessor activity of $i-j$ work.

(c) Meet the Production Requirements of Enterprises. In order to ensure the normal operation of the enterprise, the raw materials needed can not be short in a future production plan period. Reflected in the model is: The beginning of period ' $t$ ' (the stock at the end of period t-1) for material stock 'a', plus the order for material 'a' in period ' $\mathrm{t}$ ', minus the stock at the end of period ' $t$ '. The result is not less than the demand of the company for material ' $a$ ' in period ' $\mathrm{t}$ ':

$V_{t-1}+X_{t}-V_{t} \geq D_{t}$

In the above formula, $X_{t}$ is the amount of material ' $\mathrm{a}$ ' ordered by enterprise in the period ' $\mathrm{t}$ '. $V_{t-1}$ is inventory of the initial period ' $t$ '. $V_{t}$ is the inventory of material ' $\mathrm{a}$ ' at the end of period ' $\mathrm{t}$ '. $D_{t}$ is the demand for material ' $a$ ' in the period ' $t$ '.

(d) Satisfy Supplier's Supply Capacity Requirements. Satisfy the fullness of the supplier's production line. Each time a user orders his supplier, the $X_{t}$ is at least $L_{\min }$ (except for the last order of each item), and the maximum quantity of goods ordered by the supplier is $L_{\max }$.

Constraint: $L_{\min } \leqslant X_{t} \leqslant L_{\max }$

(e) Transport economy constraints. The cost of transportation depends on the means of transport and the distance of travel. Once the supplier and demand side have been identified, the means of transport can be determined by traffic conditions and production needs. Therefore, the corresponding fixed costs per shipment and the variable costs of transportation per unit of product (such as fuel costs) are also determined. At this time, the unit variable cost of goods transport unchanged, and the fixed cost of each share of goods to be affected by the full extent of the transport vehicle. The quantity of goods carried is inversely proportional to the fixed cost shared by each unit of goods. When the quantity of transportation increase, the unit costs of transport is decrease. Therefore, in the transport of products as much as possible to make the goods fully loaded to reduce transportation costs. Therefore, each order of goods should be an integral multiple of transport capacity.

$X_{t}=K \times N$
The meaning of $X_{t}$ is the same as above; $K$ means the transport capacity of the transport unit. $N$ is a natural number variate.

Based on the above analysis, considering the supply capacity of suppliers and the progress of production, the optimization model of materials ordering scheme is:

$$
\begin{gathered}
\text { Minimize }=T C_{0}+T C_{1}+T C_{2}+\mathrm{TC}_{3} \\
\text { s.t. }\left\{\begin{array}{c}
T_{E i-j} \leq T_{S i-j} \leq T_{E i-j}+R_{S i-j} \\
\max \left\{T_{s h-i}+t_{e h-i}\right\} \leq T_{S i-j} \leq T_{t i-j-j} \\
V_{t-1}+X_{t}-V_{t} \geq D_{t} \\
L_{\min } \leq X_{t} \leq L_{\max } \\
X_{t}=K \times N
\end{array}\right.
\end{gathered}
$$

\section{Solution of the Model}

Genetic algorithm (GA) as an efficient parallel global optimization search algorithm, it is used more and more widely for solving many practical problems. The network project for large-scale projects is extremely complex, in which case is suitable for solving the model using genetic algorithms.

The paper needs to solve the following four key problems, then solve the genetic algorithm:

a. Determine the variable representation scheme, which means coding problems;

b. Determine the fitness function;

c. Determine the model's constraint function;

d. Determine the operating parameters and variables of the genetic algorithm.

The final calculation is done by the computer.

\section{Collaborative Procurement of Automobile}

\section{Manufacturing Supply Chain AND Positive ANALysis of} WAREHOUSE MANAGEMENT

After the text edit has been completed, the paper is ready for the template. Duplicate the template file by using the Save As command, and use the naming convention prescribed by your conference for the name of your paper. In this newly created file, highlight all of the contents and import your prepared text file. You are now ready to style your paper; use the scroll down window on the left of the MS Word Formatting toolbar.

From the perspective of complex systems science, the basic idea of collaborative management of automotive supply chain is to recognize the law of self-organization, follow selforganization, and dynamically adjust it in an organized way to transform the system into self-organization. Scientifically looking for the parameters that govern the synergies of the automotive supply chain system, by applying external pressure to the parameters to change the control parameters, prompting the system to achieve synergy (self-organizing transformation mechanism). Collaborative management of the automotive 
supply chain, designed to make all aspects of the automotive supply chain to achieve coordinated operation of the operation. It needs a set of scientific methods to diagnose the synergy of the automotive supply chain, find the order parameters that affect the synergy of the system, and adopt the corresponding organized strategy to support and amplify the benign fluctuations, inhibit or attenuate the adverse fluctuations, Organizational means to optimize the process of selforganization to enhance the degree of synergy of the system. Vehicle supply chain collaborative management model shown in Fig. $1^{[14]}$.

With the deepening of globalization, the automotive supply chain has shown more and more obvious characteristics of globalization. Supply chain of automobile manufacturing industry is different from other manufacturing supply chains. The automobile supply chain is dominated by vehicle manufacturers, and the trend of automobile manufacturing industry is global collaborative design and manufacturing. There are a large number of factories around the world which have strong dependence on the automotive supply chain. Therefore, the coordinated management of the automotive supply chain is of crucial importance and is indispensable under the synergic development trend of the automotive supply chain.

Collaborative management of automotive supply chain requires core automobile manufacturers to integrate the entire automotive supply chain process. Through the functional integration of automotive logistics, process integration and resource integration to fully integrate the automotive industry supply chain. Use of automotive supply chain information system platform to achieve information collection and release, tracking the automotive supply chain logistics operation. The establishment of a financial management system based on ecommerce environment, the development of integrated data warehouse, data analysis tools to provide effective information audit and analysis. Improve and optimize collaborative management of e-commerce processes such as customer order execution, purchasing, manufacturing, inventory control, and logistics and distribution ${ }^{[15]}$.

Auto manufacturers start from the planning and formulation of the plan, forming a strategic match in the procurement of raw materials, supplier management, storage management, production distribution and service process. Thus finding a balance between meeting customer needs, speeding response times and reducing operating costs. This enables synergies across all business units, such as new product development, manufacturing operations, marketing, distribution logistics, customer service across the value chain, and support functions such as finance, information technology, and human resources. At the same time, this paper considering establishes an ecommerce information platform for auto supply chain among vehicle manufacturers, component suppliers, third-party logistics service providers and sellers, forming a dynamic automotive supply chain alliance through the coordination and sharing of information and knowledge. Vehicle manufacturers as the core supply chain enterprises, according to customer orders for production arrangement, material procurement, delivery arrangements, to determine the appropriate knowledge sharing strategy. The key process of cross-organization automobile supply chain logistics and internal production logistics involved in the production process is also identified. The main process is purchasing, production and sales.

The e-commerce information platform of automobile supply chain will share the information of dealers, consumers, suppliers and other strategic partners and realize the eprocurement of parts and components through e-commerce information platform. Then by the third-party logistics company coordinated delivery to the vehicle manufacturer's warehouse, distribution center. JIT suppliers and suppliers of parts sorted according to the dynamic coordination of automotive supply chain information delivered directly to the vehicle assembly line, so as to achieve zero inventory, supplier management inventory advanced logistics mode, reducing logistics costs ${ }^{[16]}$.

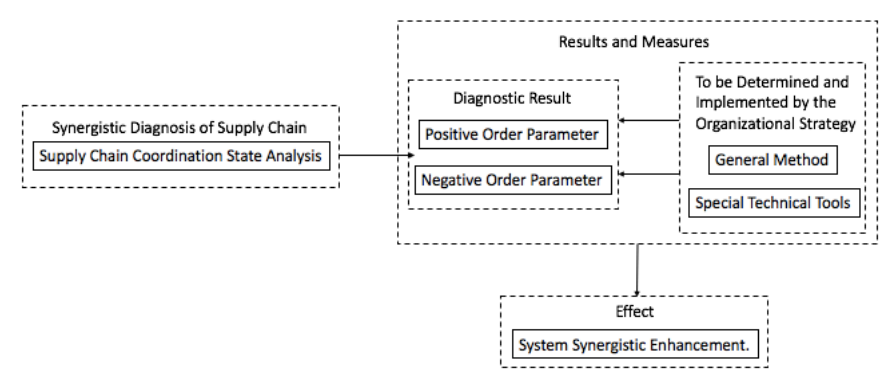

Fig. 1. Vehicle supply chain collaborative management model

\section{CONCLUSION}

Enterprise supply chain collaborative procurement management implementation strategy, different outsourcing of materials for different management strategies and select the appropriate supplier. Enterprise supply chain collaborative warehouse management, through the establishment of warehouse management model and the use of scientific methods for the production process required materials and tools and equipment supply, use and management of rational planning, organization, deployment and control. With a lower cost, timely, appropriate and appropriate supply of supplies needed to ensure the smooth progress of production. In the process of synergistic implementation of supply chain, supply chain members and supply chain leaders change the concept of supply chain management, the decomposition and integration of member value network and the selection of suitable partners and other factors to ensure the smooth implementation of enterprise supply chain collaborative management.

\section{REFERENCES}

[1] D. L. Anderson, H. Lee, C.E. Starr, et al., "Supply Chain Leadership and the High-Performance Business,” Supply Chain Practice, 2004, 6(4):414.

[2] T. Ito, M. R. Salleh, “A Blackboard-based Negotiation for Collaborative Supply Chain System,” Journal of Materials Processing Technology, 2000, 107: 398-403 
[3] ARC Advisory Group, "Collaborative Manufacturing Management Strategies,” ARC Strategies, 2002(7): 101-105

[4] R. McIvor, P. Humphreys, L. McCurry, "Electronic Commerce: Supporting Collaboration in the Supply Chain,” Journal of Materials Processing Technology, 2003, 139:147-152

[5] M. Türkay, C. Oruç, K. Fujita, et al., "Multi-company collaborative supply chain management with economical and environmental considerations," Computers \& Chemical Engineering, 2004, 28(67):985-992.

[6] H. Akkermans, P. Bogerd, J. Doremalen, "Travail, transparency and trust:a case study of computer-supported collaborative supply chain planning in high-techelectronics," European Journal of Operational research, 2004,153: 445-456

[7] D. Yi, "Stochastic Demand Oriented Two - Stage Inventory Cooperative Control Modeling Analysis," Nanchang College of Water Science, 2003, 4: $34-37$

[8] X. Tang, Y. Huang, "SCM Collaborative Management Strategy and Model Evaluation," Intelligence Magazine, 2005 (1): 88-90

[9] S. Liu, "Research on Supply Chain Collaborative Management in Ecommerce Environment," Science and Technology Progress and Policy, 2005 (10): 166-167
[10] J. Tang, G. Chen, "The Internal Motivation and Scale Analysis of Supply Chain Collaboration," Journal of Northwest Sci-Tech University of Agriculture and Forestry, 2005 (05): 44-47

[11] C. Zhang, J. Ren, H. Yu, "Research progress on supply chain collaborative management," Systems Engineering, 2005 (4): 1-6

[12] S. Chen, S. Shen, "Collaborative Cost Management of Automotive Supply Chain Management Based on Target Cost Approach," 2006(4):72-73

[13] Q. Sun, Y. Wang, "Research on Cooperative Management of Supply Chain of Automobile Industry Based on Value Net," Shandong Social Sciences, 2010(5):136-138

[14] S. Chen, "Study on Synergistic Technology of Automobile Parts Supply Chain,” Logistics Technology, 2006 (3) :168-170

[15] T. Feng, "E-commerce Research on Supply Chain Management of Automobile Industry,” China Soft Science, 2001 (2): 105-107

[16] X. Liu, J. Zhang, "The status quo and prospect of collaborative procurement supply chain management in automobile industry," Logistics Technology, 2005 (9) :132-134 